\title{
Introduction to Special Issue for 20th Anniversary of the NIA Centers for the Demography and Economics of Aging
}

\author{
John G. Haaga • Richard Suzman
}

Received: 9 January 2015 / Accepted: 19 January 2015 / Published online: 13 February 2015

(C) Springer Science+Business Media Dordrecht (outside the USA) 2015

This special issue of the Journal of Population Ageing celebrates the 20th anniversary of the NIA Centers on the Demography and Economic s of Aging, publishing a set of five invited papers by distinguished scholars based on their presentations at the 2014 session of the RAND Summer Institute on Aging. We, and the Journal editors, thought that this would be an appropriate and useful tribute to the work of the centers, since the RAND Summer Institute (RSI) is almost the same age as the centers and over the years has attracted center affiliates both as master lecturers and as trainees. The five articles in this issue, though not a comprehensive review of the field, provide a sense both of the advances of the last two decades and of the great work still to be done.

The centers program began as supplements to Demography Centers funded by the National Institute of Child Health and Human Development, which along with the National Institute on Aging is part of the National Institutes of Health. With one exception, housed at the National Bureau of Economic Research, the early centers were very focused on demography, and they were fractionated with few common projects across centers. The idea behind the RSI was to provide basic lectures in each of several areas both to attract new scholars into research on aging and to form a more integrated research program. The first forum was held in Chicago in the afternoon prior to the start of the Annual Meeting of the Population Association. On the plane to Chicago one of us (RS) noticed that Dr. Robert Wallace, a physician epidemiologist, was his way to the University of Iowa, and cornered him and persuaded him to delay his trip and give an impromptu presentation on epidemiology of aging - one of the best that afternoon.

The Centers have become much more integrated than at first. They work together on many projects, sharing costs and contributing ideas. They now form the essential infrastructure for the social sciences related to aging. The RSI has undergone a similar

\footnotetext{
J. G. Haaga $(\square) \cdot$ R. Suzman

Division of Social and Behavioral Research, National Institute on Aging, Gateway Building, suite 533, 7201 Wisconsin Avenue, Bethesda, MD 20892, USA

e-mail: John.Haaga@nih.gov

R. Suzman

e-mail: SuzmanR@nia.nih.gov
} 
broadening, as several subfields of psychology have been integrated into the RSI, and a separate but contiguous "Mini-Medical School for Social Scientists" has been added to provide a taste of biology, clinical medicine and genetics.

Participants in the RSI are selected competitively and need not be affiliated with one of the centers, and faculty are invited from research centers around the world, but inevitably the Centers are heavily represented at all levels every year. The topics discussed at the Institute dovetail nicely with the year-round work of the centers. Through funding of pilot projects, the centers have helped young scholars get established in productive careers or lured talented senior researchers into aging. Lists of seminars and visiting fellowships, or of publications produced by center affiliates, would show the same progress that the master lectures at the summer institute review. The centers have celebrated milestone anniversaries at the summer institute, and the tradition has grown of marking anniversaries with special issues of leading journals: Demography twice, (vol 34, number 1, February 1997, and volume 47, supplement, 2010) and Population and Development Review (Waite 2004).

The progress of the last 20 years, both in the data infrastructure and the interdisciplinary scope of research in this field, can be traced by comparing the most recent programs for the Summer Institute with the original in 1994. RAND has posted the programs for all past Summer Institutes online at http://www.rand.org/labor/aging/rsi/ demography.html

James Vaupel gave a 1994 Master Lecture on mortality of the oldest-old, beginning a Summer Institute tradition of luring young scholars into aging by presenting paradoxical findings challenging orthodoxy (in this case, the universality of the smooth Gompertz curve.) Burton Singer took on in 1994 what was even then a vast topic, the relationship between socioeconomic status and health. It had been known since pioneering studies of the 1970 s that social connections profoundly influence health at older ages. In this special issue, the article by Wong and Waite (2015) takes advantage of a data source, the National Social Life, Health and Aging Project, which provides much greater detail about the social environment than was available two decades ago. They show that aspects of the quality of relationships matter more than the quantities ("connectedness") assessed in earlier studies, and that the quality of marriage and intimate partnerships affects health. The study of effects of social environment on health has always been hampered by the difficulty of sorting out bidirectional causation; rich longitudinal data make possible the estimation of models that capture the effects of health on one's social relationships as well as the converse.

That first Summer Institute included several sessions devoted to introducing new data sets to support research, including the Health and Retirement Study and supplements to the Panel Study on Income Dynamics. The PSID was not strictly speaking "new" - results from PSID had figured prominently in the policy debates leading up to the 1996 welfare reform law. But the use of PSID for research on aging was new. The interest in global aging was also clear from the start. But the session on "New Datasets: International" presented a series of studies in Asia, among which some shared family resemblances (the Malaysia and Indonesia Family Life Studies; the Surveys of the Health and Welfare of the Elderly in Asia). None of the international data sets were harmonized at that time with the large studies in the United States. Researchers could draw some rough parallels across the Pacific but the available data could not support truly comparable cross-national comparisons of models estimated on micro-level data. 
In 1994, James P. Smith, David Wise, Angus Deaton, and Thomas Juster gave the Master Lectures on Economics of Aging, of which one subtitle provided a reasonable summary of worldwide trends: "More old people living longer, saving less, working less." This theme is brought up to date in this issue by the article on "Health and Work at Older Ages" by Milligan and Wise (2015). They show that the improvement in health at older ages, measured by age-specific mortality rates rather than just the change in aggregate measures like life expectancy, has been accompanied by a decline in labor force participation at any given level of health, over three decades. Their view of health-age, or capacity to work, adds a fresh perspective to the more familiar calendar-age view of these rates. Their use of the Human Mortality Database, a longstanding project supported in part by the Berkeley Center for Economics and Demography of Aging, provides a good example of the return on investments in data infrastructure.

David Rush's 1994 presentation on nutrition and aging began a tradition of interest in the biological mechanisms underpinning relationships at the population level between social characteristics and morbidity and mortality. In recent years this feature of the Summer Institute has grown into a separate two-day Mini-Medical School for Social Scientists preceding the Demography and Economics sessions. Crimmins (2015) article in this issue illustrates the extent, and the analytic value, of crossnational coordination of the collection of biological data in longitudinal population studies. These data make feasible the study of the pathways through which the social environment affects health outcomes over the lifecourse. This is an area to which the center Dr. Crimmins directs at the University of Southern California has made fundamental contributions. Her analysis spans populations at very different stages of the epidemiologic transition, ranging from an Amazonian people still subject to the massive burden of parasitic and infectious diseases typical of our ancestors for most of human evolution to people in rapidly developing middle-income countries to those in established post-industrial economies. Harmonized data covering much of the lifecourse for most of the countries increase confidence in her conclusion that earlylife nutritional conditions are less important than concurrent obesity for explaining cardiovascular risk... a conclusion which highlights the public health significance of a worldwide rise in obesity rates.

Population aging has heightened interest in cognitive changes that accompany aging, including impairment and ultimately dementia caused by neurodegenerative diseases, notably Alzheimers. Until recently the study of cognitive aging and of the epidemiology of dementia has been sorely constrained by the lack of good longitudinal data representative of large populations. Cognitive aging is inherently a longterm process; cross-sectional analyses were always severely constrained by the inability to distinguish cohort differences from true effects of aging. The article by Rickenbach et al. (2015) in this special issue on memory self-assessments would not have been possible in 1994; it uses data collected on up to six occasions over 10 years by the Health and Retirement Study, complemented by rich data including neuroimaging from the Midlife in the United States (MIDUS II) study. Their finding that self-assessment of memory problems and of recent decline in function are very weakly related to actual performance or change in performance; this is a fundamental problem for a health care system which relies overwhelmingly on self-assessment and presentation for diagnosis of cognitive impairment. 
The epidemiology of dementia is especially important for projections of spending on health and social care for the elderly, a growing burden around the world. Hurd et al. (2015) had shown in earlier work that in a full social cost accounting, dementia care is already a greater burden for the United States economy than the care of the major killers, heart disease and cancers. In the new research published in this special issue, they show that the trend of lower incidence of dementia found in multiple recent population studies, including the HRS for the United States, could have a great impact on the costs to society. By one measure of the value of informal care, for example, the total monetary costs of dementia care would be "only" a little more than 300 billion dollars in the United States in the year 2040 with continued decline in incidence, as opposed to over 500 billion dollars without the decline. In sensitivity analyses, however, they show that much depends on trends in the prevalence of comorbidities, an area that needs more attention from epidemiologists. This decline in dementia still needs further confirmation and explanation; if it holds up it is hard to conceive of any better news both for individuals facing old age and societies facing demographic transformation.

Population aging is in one sense old news for demographers and economists. The year 2014 was the twentieth anniversary, not only of the Economics and Demography of Aging Centers, but also of the landmark World Bank report Averting the Old Age Crisis (James et al. 1994.) The year 2015 is the 90th anniversary of the classic article by Lotka and Dublin (1925), which might be seen as the wellspring for demography of aging, showing that negative inherent growth rates were inextricably leading to a new, older age structure for the US population. But as the articles in this special issue demonstrate, once one gets past, or beneath, the generalities, aging at both individual and population levels is still full of surprises. The data sources featured in the analyses included in this special issue provide raw material.

In the two decades since the first summer institute, much has changed. We have a new infrastructure of longitudinal surveys starting with the Health and Retirement Study HRS) which is approaching 25 years of data. Plus there has been a viral spread of HRS-type surveys across the world -England (ELSA), Europe (SHARE), Mexico (MHAS), China (CHARLS), India (LASI), plus several not funded by NIA such as Japan, Ireland TILDA), Northern Ireland (NICOLA), Brazil (ELSI), with more developing such as Scotland. Also relate are the Surveys of Health and Aging (SAGE), organized by the World Health Organization in and funded by NIA in six countries (China. India, Russia, Mexico, Ghana and South Africa). Harmonization of certain elements of the surveys is under way. NIA training grants as well as the centers and the RSI have produced a set of researchers far more adept at interdisciplinary research than in 1994. This has also been reflected in NIA's funded grants, especially in the larger multi project and often interdisciplinary Program Projects. Psychology has become more intertwined and closer to economics and demography, and new fields such as behavioral economics and neuroeconomics have developed. But by far the newest and potentially the most radical development has been the introduction of genetics into social and behavioral science; Several of NIA's surveys have been genotyped, including the HRS and ELSA, and the data are available. It is still too early to say what the effect of introducing genetics into behavioral science will amount to, but by discovering behavioral pathways, genetics could transform our science. 
The research centers whose anniversary provided the occasion for this collection provide an encouraging environment. The best days for research on aging are still ahead of us.

\section{References}

Crimmins, E. (2015). Physiological differences across ageing populations reflecting early life and later life nutritional status and later life risk for chronic disease. Journal of Population Ageing, Special issue: Research highlights from the 20th Anniversary of the NIA Demography Centers, 8, 1-2.

Hurd, M., Martorell, P., Langa, K. (2015). Future monetary costs of dementia in the United States under alternative dementia prevalence scenarios, Journal of Population Ageing, Special issue: Research highlights from the 20th Anniversary of the NIA Demography Centers. 8, 1-2.

James, E., Demirguc-Kunt, A., Fox, L., et al. (1994). Averting the old-age crisis: policies to protect the old and promote growth. New York: World Bank by Oxford University Press.

Lotka, A. J., \& Dublin, L. I. (1925). On the true rate of natural increase. Journal of the American Statistical Association, 20, 305-339.

Milligan, K., Wise, D. (2015). Health and work at older ages: using mortality to assess the capacity to work across Countries. Journal of Population Ageing, Special issue: Research highlights from the 20th Anniversary of the NIA Demography Centers, $8,1-2$.

Rickenbach, E-H., Agrigoroaei, S., Lachman, M. (2015). Awareness of memory ability and change: In(Accuracy) of memory self-assessments in relation to performance. Journal of Population Ageing, Special issue: Research highlights from the 20th Anniversary of the NIA Demography Centers. 8, 1-2.

Waite, L.J., ed (2004). Aging, health and public policy: demographic and economics perspectives, Supp to vol 30. Population and Development Review.

Wong, L., Waite, L. (2015). Marriage, social networks, and health at older ages. Journal of Population Ageing. Special issue: Research highlights from the 20th Anniversary of the NIA Demography Centers. 8, 1-2. 